worryingly high, I think that the rate of one in three is misleading as it assumes a constant rate of termination throughout ages 15-44. This is not the case at present, as among women aged 35 and over the rate reduces to about 4 terminations per 1000 women. If the number of terminations is calculated on the basis of the three age groups 15-19, 20-34, and 35-44 it results in a rate of 200/1000 in the 30 years. This, when corrected for women who have had a termination previously, results in a figure of about one in six women having a termination in their lifetime.

PAT OWEN

Department of Public Health Medicine.

Cornwall and Isles of Scilly District Health Authority,

Truro TR1 $1 \mathrm{NR}$

1 Drife JO. One in three. BMY 1991;303:653. 14 September.

AUTHOR'S REPLY, - The abortion rates for older women have been fairly constant since 1969 at just over $7 / 1000$ women aged $35-39$ and 3/1000 women aged 40-44. These rates fell slightly in the late 1980 s, possibly becaus: nowadays almost half of British women over 35 have been sterilised or have a partner who has beer terilised.

Nevertheless, the unual abortion rate for women aged 16-24 is now 24/1000. Over this nine year period there is therefore an overall rate of $216 /$ 1000 , which means that at least 1 in 5 women will have an abortion before the age of 25 .

After I wrote my article I found a recent comprehensive review by Botting, of the medical statistics division of the Office of Population Censuses and Surveys, which included a calculation of the "projected average lifetime abortion rate." Based on the rates in 1969-74, 28 women in every 100 would have an abortion at some time in their lives, whereas baced on the rates for 1985-9 the figure rose to 42 in every 100 . Therefore one in three may now be an underestimate, not an overestimate.

JAMES OWEN DRIFE

Department of Obstetrics and Gynaecology,

University of Leeds.

Leeds LS2 9NS

1 Botting B. Trends in abortion. Population Trends 1991;64:19-29.

\section{Topical anaesthesia in upper gastrointestinal endoscopy}

SIR, - We were pleased to see that Dr S Y Chuah and colleagues found that topical anaesthesia before upper gastrointestinal endoscopy was of no obvious benefit. ${ }^{1}$ Although some potential hazards of premedication with lignocaine spray to the pharynx were mentioned (methaemoglobinaemia, risk of aspiration, and damage to the ozone layer), we believe that the most serious potential hazard was not addressed.

Lignocaine is a powerful drug, and overdose can lead to depression of the cardiovascular, respiratory, and central nervous systems. ${ }^{2}$ Peak blood concentrations of over $5 \mu \mathrm{g} / \mathrm{ml}$ - the level thought to give rise to toxic reactions-may occur after lignocaine has been applied to mucosal surfaces, ${ }^{34}$ and fatalities and severe reactions have been described after such administration. ${ }^{5-7}$

Recent studies have shown significant episodes of hypoxia, arrhythmias, and myocardial ischaemia after upper gastrointestinal endoscopy. ${ }^{8}$ Such events are potentially aggravated by the concurrent administration of lignocaine.

Another potentially dangerous factor is that doctors have been shown to be unaware of basic information regarding the amount and maximum recommended doses of local anaesthetics. ${ }^{9}$ A recent survey that we carried out of 78 medical staff who regularly performed bladder catheterisation showed that all used lignocaine gel and yet only one person was aware of how much he was administering.

As no obvious advantage was shown for the patient or practitioner by premedicating patients with lignocaine spray to the pharynx before upper gastrointestinal endoscopy, we believe that this practice, which may be an important factor in morbidity or mortality associated with such a procedure, should now be abandoned.

M T ALI

Department of Anaesthesia

Department of Anaesthesia,

A W MURRAY

Leicester Royal Infirmary LE1 5WW

S G TORDOFF

1 Chuah SY, Crowson CP, Dronfield MW. Topical anaesthesia in upper gastrointestinal endoscopy. BMF 1991;303:695. (21 September.

2 Rang HP, Dale MM. Pharmacology. Edinburgh: Churchill Livingstone. 1990:587.

3 Ouellette RD, Blute R, Jaffee S, Bahde C. Plasma concentrations of lidocaine resulting from instillation of lidocaine jelly into genitourinary tract prior to cystoscopy. Urology 1985;25: $490-1$

4 Scot DB "Maximum recommended doses" of local anaesthetic drugs. Anaesthesia 1989:63:373-4.

5 Adriani J, Campbell D. Fatalities following topical application of local anesthetics to mucous membranes. JAMA 1956;162 $1527-30$

6 Dix VW, Tressider GC. Collapse after use of lignocaine jelly for urethral anaesthesia. Lancet 1963;i:890.

Heath PK, Tometzki AJP, Gerrard DMP. Status epilepticus following rectal administration of lignocaine gel in a 2 month old baby. $B M \mathcal{F}$ 1989;298:1592.

8 Murray AW, Morran CG, Kenny GNC, Macfarlane P, Anderson $J R$. Examination of cardiorespiratory changes during upper gastrointestinal endoscopy. Anaesthesia 1991;46:181-4 9 Scrimshire JA. Safe use of lignocaine. BM7 1989;298:1494.

SIR,-It is unfortunate that Dr S Y Chuah and colleagues' thoughtfully designed and long overdue investigation of the effectiveness of topical anaesthesia in upper gastrointestinal endoscopy will not prove useful in modern endoscopic practice': the mean dose of intravenous midazolam given is much larger than that now used by many, and probably most, endoscopists for straightforward upper gastrointestinal endoscopy and exceeds the usual range described in the data sheet. ${ }^{2}$ The result of a repeat study in which about half the dose of midazolam was given would be valuable.

Shotley Bridge General Hospital

A F MACKLON

Consett DH8 0NB

1 Chuah SY, Crowson CP, Dronfield MW. Topical anaesthesia in upper gastrointestinal endoscopy. BMF 1991;303:695. (21 September.

Association of the British Pharmaceutical Industry. ABPI date sheet compendium. London: DataPharm, 1990:1404.

\section{Misuse of temazepam}

SIR,-Professor D G Grahame-Smith recently gave a warning about misuse of temazepam,' and Messrs A N Meshikhes and J S Duthie reported erythematous swelling after injection of temazepam. ${ }^{2}$ We report a case of severe rhabdomyolysis, oedema, and macular rash after misuse of temazepam.

A 28 year old woman presented four hours after attempting to inject into the right femoral artery $80 \mathrm{mg}$ temazepam extracted from liquid filled capsules. She developed a purple macular rash, severe oedema, and exquisite tenderness of the whole of the right leg, which persisted for five days. Serum creatine kinase activity was 5900 IU/1 (normal range 10 to $90 \mathrm{IU} / \mathrm{l}$ ) and rose to $25000 \mathrm{IU} /$ five days after the injection before falling to $311 \mathrm{IU} / 116$ days after admission. She was treated with intravenous fluids to maintain a diuresis of $100 \mathrm{ml} / \mathrm{h}$, and her renal function did not deteriorate, creatinine concentrations remaining normal throughout. She made a complete recovery.
In our case the early rise in creatine kinase activity indicated focal rhabdomyolysis. Although this phenomenon has been noted after an oral overdose of nitrazepam and doxepin, ${ }^{3}$ we believe this to be the first report of rhabdomyolysis after injection of temazepam.

An increasing number of addicts are misusing temazepam. Clinical awareness of the diverse manifestations of this and measurement of serum creatine kinase activity to detect rhabdomyolysis may help avert potentially severe side effects.

M M T HUDSON $M$ EDMONDS

P J WATKINS

Dulwich Hospital

London SE22 8PT

Grahame-Smith DG. Misuse of temazepam. BMF 1991;302:1210. (18 May.)

Meshikhes AN, Duthie JS. Misuse of temazepam. $B M J$ 1991;303:478. (24 August.)

3 Hojgaard AD, Andersen PT, Moller-Petersen J. Rhabdomyolysis and acute renal failure following an overdose of doxepin and nitrazepam. Acta Med Scand 1988;223:79-82.

\section{Low cholesterol and coronary heart disease}

SIR,-The conclusion of Dr Zhengming Chen and colleagues - and the title of the article, "Serum cholesterol concentration and coronary heart disease in population with low cholesterol concentrations"- misses a very important finding.

Notwithstanding their assertion that "there was no good evidence of an adverse effect of cholesterol on other causes of death," the researchers state in their results that "there was a significant inverse relation between serum cholesterol concentration and all deaths from non-vascular, non-cancer causes $(p<0.05)$." Moreover, all cause mortality (expressed as the ratio of observed to expected deaths) did not vary across the quartile groups of cholesterol concentration $(1 \cdot 1$ in the lowest quartile to 0.97 in the highest) - in contrast to the impressive figures for differences in deaths from coronary disease.

In my experience people are interested in ways of reducing "all cause" mortality rather than of shifting the cause without affecting their lifespan; Dr Chen and colleagues' study adds to the large body of evidence that cholesterol concentration is no closely linked to overall mortality - and that a low cholesterol concentration merely makes death from a non-cardiac cause likely.

London SE21 8HS

T H LEIGH

1 Chen Z, Peto R, Collins R, McMahon S, Lu J, Li W. Serum cholesterol concentration and coronary heart disease in population with low cholesterol concentrations. BMT 1991;303:276-82. (3 August.)

AUTHORS' REPLY - Our study in an Asian population with low cholesterol concentrations indicates a strong positive relation between serum cholesterol concentration and deaths from coronary heart disease $(2 p<0.001)$ with no evidence of any "threshold" within the range studied (about $3 \cdot 8-4 \cdot 7 \mathrm{mmol} / \mathrm{l}) .^{\prime}$ In Western populations the average cholesterol concentration is higher than that in Shanghai and few people have a concentration that is persistently as low as $4.7 \mathrm{mmol} / \mathrm{l}$. This implies that very few people in Western populations have a biologically normal (as opposed to a laboratory "normal") cholesterol concentration and that for most of them a lower cholesterol concentration should eventually confer a lower risk of coronary heart disease.

To assess any causal relation between serum cholesterol concentration and total mortality, especially in a population in which only a small proportion of the deaths are due to coronary 